\begin{tabular}{|c|c|}
\hline Title & The effect of change leadership on employee attitudinal support for planned organizational change \\
\hline Author(s) & Onyeneke, Gechinti Bede; A be, Tomokazu \\
\hline Citation & $\begin{array}{l}\text { Journal of organizational change management, 34(2), 403-415 } \\
\text { https://doi.org/10.1108/JOCM-08 2020-0244 }\end{array}$ \\
\hline Issue Date & $2021-10-29$ \\
\hline Doc URL & http:/hdl.handle.net/2115/83114 \\
\hline Rights & CC BY-NC 4.0 \\
\hline Rights(URL) & https://creativecommons.org/icenses/by-nc/4.0/ \\
\hline Type & article (author version) \\
\hline File Information & HUSCA P98106.pdf \\
\hline
\end{tabular}

Instructions for use 
This file contains the author accepted manuscript (AAM) version to the article cited below. It may contain minor differences from the journal's pdf version.

Onyeneke, G.B. and Abe, T. (2021), "The effect of change leadership on employee attitudinal support for planned organizational change", Journal of Organizational Change Management, Vol. 34 No. 2, pp. 403-415. https://doi.org/10.1108/JOCM-08-2020-0244

Publisher: Emerald Publishing Limited

Copyright (C) 2021, Emerald Publishing Limited

Deposit licences

Emerald allows authors to deposit their AAM under the Creative Commons Attribution Noncommercial International Licence 4.0 (CC BY-NC 4.0). To do this, the deposit must clearly state that the AAM is deposited under this licence and that any reuse is allowed in accordance with the terms outlined by the licence. To reuse the AAM for commercial purposes, permission should be sought by contacting permissions@emeraldinsight.com.

For the sake of clarity, commercial usage would be considered as, but not limited to:

o Copying or downloading AAMs for further distribution for a fee;

o Any use of the AAM in conjunction with advertising;

o Any use of the AAM by for promotional purposes by for-profit organisations;

o Any use that would confer monetary reward, commercial gain or commercial exploitation.

Emerald appreciates that some authors may not wish to use the CC BY-NC licence; in this case, you should deposit the AAM and include the copyright line of the published article. Should you have any questions about our licensing policies, please contact permissions@emeraldinsight.com. 


\title{
The Effect of Change Leadership on Employee Attitudinal Support for Planned Organizational Change
}

\author{
Gechinti Bede Onyeneke ${ }^{1)}$ and Tomokazu Abe ${ }^{2)}$ \\ 1) Graduate School of Economics and Business, Hokkaido University, Sapporo, Japan \\ 2) Faculty of Economics and Business, Hokkaido University, Sapporo, Japan
}

\begin{abstract}
Purpose - to examine how change leadership activities help bring about employee support for planned organizational change.

Design/methodology/approach - Using a non-experimental quantitative research design, and a selfadministered Likert-type questionnaire survey, the study sourced data from employees in an organization undergoing significant change. Data analysis was by Structural Equation Modeling (SEM).

Findings - Change leadership behaviors bearing on; visioning, communication, participation, support, and concern for change participants' interests were found to be of significant importance in ensuring employee buy-in and support for planned change efforts. Although change leadership had no direct effect on employees' behavioral intentions to support change, it was strongly related to employee cognitive appraisal of change. The relationship between change leadership and employee behavioral intentions to support planned change was serially mediated by employee cognitive appraisal and emotional response towards the planned change event.
\end{abstract}

Practical implications - In appraising planned organizational change efforts, managers tend to focus on employee behaviors towards the change instead of conditions that drive such behaviors. This study underscores the need to focus on employee attitudes as precursors to desired behavior towards change.

Originality/value - Prior research suggest that change leadership behaviors affect employee attitudinal reactions to change but lacked empirical validation. By applying a multidimensional approach to attitude and investigating its hierarchy of effects, this study enhanced the accuracy in explaining the influence change leadership has on employee attitudinal support for change.

Keywords - Planned Organizational Change, Change Leadership, Support for Change, Attitude towards Change.

Paper type: Research paper

\section{Introduction}

Business environments are constantly changing, and such changes have implications for the continued performance and survival of today's organizations. However, keeping pace with changes occurring within their environment is often challenging for organizations. When organizations fail to create continuously adaptive systems and misalignment arises between organizations and environmental demands, planned organizational change becomes necessary for organizations to respond to environmental changes (Burke, 2017; Weick, 1999)

Extant literature on planned organizational change suggests a rare experience in the successful implementation of organizational changes (Beer and Nohria 2000; Hughes and Ford, 2016). Uncertainties and anxieties for potential threats on employees regarding the planned changes (Bailey and Raelin, 2015), and lack of cooperation from organizational members (Piderit, 
2000), are recognized as reasons many organizational change efforts fail. Given that the outcome of organizational change is largely dependent on the actions of its members, it is imperative to resolve such change-related concerns to encourage employees' cooperation and support for planned organizational change.

Scholars regard facilitating employee support as a fundamental role of leaders during organizational change events. Specifically, planned organizational change requires leadership to enable employees' buy-into and support planned change efforts (Burke, 2017; Stouten et al., 2018). Despite the numerous researches suggesting that leaders can help shape employee reactions towards change, a major concern persists regarding whether and how change leaders can influence employee attitudinal and behavioral support for planned organizational change (Oreg and Berson, 2019). Such relationships remain open to quantitative validation, as previous studies have been mainly conceptual (Hughes and Ford, 2016).

In this paper, therefore, we sought to understand how and under what conditions change leadership behaviors (a concept rooted in normative change process models) affect employee support for change (operationalized as attitudinal reactions towards change). As a contribution to organizational change and leadership research, this study found a causal relationship between change leadership and employee support for change and also revealed the hierarchy of effects between employee attitudes that explain their support for planned change. Our notion of leaders herein encompasses all individuals in positional authority within an organization, viz, heads of units, divisions, departments, and top-level managers. Planned organizational change, also referred to as 'change' henceforth, implies deliberate, strategic, and goal-oriented change efforts, initiated at the higher levels of the organization designed to accomplish desired change goals.

In the next section, we briefly outline existing theories and propose hypotheses that explain how change leadership may serve as a precursor to employee support for planned organizational change. This is followed by sections on the methods, analysis, and results of the study. Finally, in the discussion section, we discuss the findings of our study and conclude by calling attention to the limitations of our study.

\section{Theoretical Background}

\subsection{Employee Attitudinal Support for Change}

Employee support is a sine qua non for the successful implementation of change. For years, scholars have focused on attitudinal constructs in explaining conditions under which employees support or resist change (Choi, 2011; Oreg and Berson, 2019; Piderit, 2000). Such attitudinal constructs weigh in on employee change-related responses viz., their cognitive responses, emotional responses, and behavioral intentions towards change events. For example, in explaining cognitive response to change, studies have focused on employee appraisal and assessment of the essence and value of change, such as employees' opinions or convictions about the appropriateness of, support for, and value of a desired change (Armenakis et al., 2007), a mindset that binds employees to a course of action towards a change (Herscovitch and Meyer, 2002), and an employee's belief of the motives for a specific change (Stanley et al., 2005). Also, to explain 
emotional responses, prior studies have focused on employees' feelings regarding pleasantness of the change (Bartunek et al., 2006), change-related stress, anxiety and fear (Smollan, 2015), anger and frustration (Kiefer 2005). Finally, researchers have also studied behavioral responses to change, such as employees' behavioral intentions to support or resist the change (Stanley et al., 2005; Szabla, 2007), and their willingness to support change (Wanberg and Banas, 2000). Others focused on overt behaviors such as employees' inquiry for information and feedback regarding a change (Ashford, 1988), active participation with regards to change (Coyle-Shapiro, 1999), compliance, cooperation, and championing behaviors in response to change (Herscovitch and Meyer, 2002), and application of change (Jones et al., 2005).

For every change event, employees experience such cognitive, emotional, and intentional attitudinal responses which become part of their decision processes on whether to resist or support the change effort (Armenakis et al., 2007; Piderit, 2000).

Furthermore, studies suggest plausible causal relationships between these different dimensions of attitude, and also that variation in evaluation along a particular attitudinal response will cause variations in others (Oreg and Berson, 2019; Piderit, 2000; Valente et al., 1998). The theory of reasoned action shows that beliefs, in conjunction with attitudes and intentions, shape individuals' overt behaviors (Fishbein and Ajzen, 1975). Valente et al.'s (1998) learning model of behavior change demonstrates a relational ordering between the dimensions of attitude, whereby cognition precedes emotion, which in turn influences behavior. The crux of such premises is that individuals first learn about a change and then develop feelings toward it, and it is based on these two change-related responses, that they develop behavioral intentions to support or resist the change. These understandings lend credence to a multidimensional approach to examining and understanding employee attitudinal support for change.

\subsection{Leading Organizational Change}

Several factors may serve as precursors to the aforementioned attitudinal responses to change, including leadership activities during change events, which are recognized as a significant driver of attitudinal responses towards change (Choi, 2011; Herold et al., 2008; Oreg and Berson, 2019; Szabla, 2007). In discussing the relevance of leadership within the context of organizational change, some studies focus on leadership actions that are situation-specific e.g., change leadership, while others look at leader behaviors that are more stable and transcend a given organizational context e.g., transformational leadership (Herold et al., 2008; Hughes and Ford, 2016).

Although highly overlapped, both concepts have significant contrasting features, and each leadership style may vary in the mechanisms through which they affect employee reactions to change (Oreg and Berson, 2019). Herold et al. (2008) explain that change leadership is tactical and focuses on leadership behaviors towards implementing specific episodic change. Conversely, transformational leadership is strategic, with effects that extend beyond a particular change situation. Unlike change leadership, it requires a long-term relationship to be established between leaders and followers through many interactions and is expected to lead to robust identification with change visions in a broad sense. Transformational leadership assumes that certain types of 
leaders will naturally handle change situations better. In contrast, change leadership assumes that through specific change-related behaviors, any leader can bring about employee support for planned change, and ultimately achieve positive results.

\subsection{Change Leadership}

Whereas a lot of empirical attention has been paid to transformational leadership, very little attention has been paid to the role and behaviors of leaders in a change context per se (Higgs and Rowland, 2011). As an event-based construct, change leadership plays an essential role in implementing changes that are planned, episodic, and top-down oriented. The term "change leadership" was coined within more recent literature (e.g., Higgs \& Rowland, 2005; Herold et al., 2008), and generally stems from change process literature, which deals with actions undertaken by change agents towards the implementation of a specific planned change. Much of change process literature focuses on the roles that managers and change agents have, as change leaders, and how through a sequential process, change leaders can influence the implementation and outcome of a change at hand. However, the diverging point of emphasis from process to leadership-oriented literature was the realization that the successful implementation of change does not occur through a linear or step-based implementation process, rather, successful change requires a complex responsive process, thus more facilitating and engaging models of leadership are preferable (Dumas and Beinecke, 2018; Higgs and Rowland, 2011).

Building on change process literature, researchers have prescribed leadership behaviors that facilitate change. These include; developing a clear and concise change vision, encouraging active participation, persuasive communication, mobilizing coalition to support and promote the change, showing concern for individuals who have trouble with the change, providing changerelated support, evaluating the change implementation, and consolidating the change successes (Armenakis and Bedeian, 1999; Battilana et al., 2010; Caldwell et al., 2004; Herold et al., 2008; Higgs and Rowland, 2005; Kotter, 1997; Szabla, 2007). The aforementioned activities are facilitated by those in change leadership positions (Kotter, 2011; Herold et al., 2008).

\subsection{The Relationship between Change Leadership and Employee Attitudinal Support for Change}

Most research on leadership behaviors during change processes are based on the theoretical argument that leaders promote change by engaging followers and shaping their attitudinal responses (Higgs and Rowland, 2011; Oreg and Berson, 2019). Leadership effectiveness in managing change is negatively related to change recipient skepticism and stress regarding the change, and positively related to implementation success (Stouten et al., 2018). Behaviors such as promoting the benefits of the change, justifying the need for the change, encouraging employee participation in decision making, fostering collaboration between employees and decision-makers, and empowering employees, are said to elicit positive attitudinal responses towards change (Szabla, 2007). Change leader's communication during change processes is theorized to address subordinate's change-related fear, by influencing their affective commitment towards change (Luo 
et al., 2016). Employees are more likely to support and champion change when they have a favorable cognitive framework of the change and believe that change efforts are needed, appropriate, and in their best interest, when they are convinced of their capability to change, and that those in authority are behind the change (Armenakis and Bedeian, 1999). Also, it is through consultation and participation in a change decision-making process that employees can appraise these change consequences and explore how they can contribute to the change effort (Oreg and Berson, 2019).

Drawing from prior studies, this study hypothesizes that employee attitudinal support for planned change will be a function of change leadership behaviors;

H1a: Change leadership behaviors during a planned change will be positively related to employee cognitive appraisal of the change.

$H 1 b$ : Change leadership behaviors during a planned change will be positively related to employee emotional response towards the change.

H1c: Change leadership behaviors during a planned change will be positively related to employee behavioral intentions to support change.

Since prior studies suggest some form of causal relationships between the multiple dimensions of attitude to change (Oreg et al. 2018; Piderit, 2000), it is hard to imagine how change leadership can lead to supportive change-related behaviors from employees when their cognitive appraisal and emotional response to the change are negative. To effectively implement change, change leaders need to assess crucial precursors to employee behavioral support for change. Armenakis et al. (2007) identified change recipients' beliefs as a fundamental precursor to behavior. They also argued the need for leaders to influence and monitor these beliefs as a way of assessing the progress of change effort. Herscovitch and Meyer (2002) suggest that a positive 'mindset' towards change will positively influence employee cooperation and support for change. Furthermore, employees' affective and emotional experiences during the change process were identified as a direct precursor to behavioral responses to change efforts (Huy, 2002). It is no surprise that employee support for change depends on changing employee perceptions and emotions about the change event, given that behaviors are cognitively and emotionally driven. From the foregoing, this study further hypothesizes a relational ordering of attitude where;

H2: Employee cognition and emotion towards a change serially mediates the relationship between change leadership and employee behavioral intentions towards a planned change.

\section{Method}

\subsection{Research Site, Sample, and Procedure}

A research site currently experiencing change, such that its employees could easily reflect on the leadership activities and describe their attitudes towards the change event motivated our site selection. The Federal Ministry of Education (FME), Nigeria, provided such a site because it was 
undergoing significant reform at the time of this study. The change under study was a "Ministerial Strategic Plan" aimed at strengthening the educational systems and improving access to, and quality of, education. The change is expected to be implemented over four years (2018 -2022). As at the time of this study, the change was in the preparation stage of change (cf. Norcross et al., 2011); as an action plan towards the change had been established, and few implementations already underway in the ministry. At this initial stage, intentions to resist or support the change are expected to be observed. Thus, this sample was appropriate for our research aim.

Data were collected from employees at the headquarters of the FME. The headquarters consisted of 1472 senior staff. This population was chosen for this study because their job deliverables directly contribute to the actualization of the ministry policies. Change participants engaged in workshop training to sensitize, monitor, and evaluate the program. To achieve accurate sampling according to the demographic requirements of the study, we employed the aid of a Deputy Director in the ministry, who provided access and support for the study. The decision to participate in the survey was voluntary. A total of 500 questionnaire surveys were randomly distributed on-site. Overall, 258 surveys were returned, given a response rate of $51.6 \%$. Upon screening the cases, 46 respondents were deleted due to more than 20 percent missing values (Hair et al., 2014), leaving 212 complete and valid cases. Of the 212 respondents, $58 \%$ were females, $85 \%$ were principal staff, while $15 \%$ were support staff. The average service tenure of all respondents was 17 years $(\mathrm{SD}=9.947)$, and $75 \%$ believed the change had a direct impact on their job in the organization.

\subsection{Instrumentation}

3.2.1 Change leadership. Change leadership was measured using Herold et al. (2008)'s change leadership scale. This scale includes seven items covering what leaders do to effectively implement a given change. Employee perceptions of leadership activities were rated on a five-point Likert scale.

3.2.2 Support for change. Employee support for change was operationalized as three dependent variables (cognitive appraisal, emotional response, and behavioral intentions). They were measured using an adaptation of Piderit (1999)'s reaction to change scale. Some items are overlapped, thus, in this paper, reverse items were deleted, and only positively worded questions that captured the respondent's perception regarding his/her attitudinal reactions towards the planned change were included. Respondents were asked to rate the extent to which they agreed with each item on a five-point scale. Further details of both measures are given in an appendix.

\section{Data Analysis}

The analysis method applied in this study was Structural Equation Modeling (SEM). After data collection, the measures were first subjected to confirmatory factor analysis (CFA) using AMOS, to evaluate the data-model fit, reliability, and validity of latent variables. A four-factor CFA model was specified in line with the study variables, and without the hypothesized relationships among 
them. The CFA model had a chi-square value of 379.267 with 224 degrees of freedom, and a significant $p$-value of 0.00 . Given the sample size, and the number of observed variables (23 items), a significant p-value was expected (Hair et al., 2014). A close examination of absolute and incremental fit indices indicated that the model had a good fit; CMIN/DF $=1.693, \mathrm{CFI}=0.964$, $\mathrm{TLI}=0.959, \mathrm{SRMR}=0.041, \mathrm{RMSEA}=0.057$. The reliability estimates $(\mathrm{CR})$ of all factors were above 0.7 , indicating adequate reliability. The model also demonstrated sufficient convergent validity, given that all standardized loading estimates were above the recommended minimum threshold of 0.5 , with most loadings averaging at 0.8 or higher, and the average variance extracted (AVE) of all factors being above 0.5. A comparison of the square root of the AVE to all interfactor correlations indicated adequate discriminant validity because the square root of AVE for each factor was greater than all inter-factor correlations (Hair et al., 2014). The result of the analysis is summarized in Table 1. Finally, we checked for common method bias in the CFA model using Podsakoff et al.'s (2003) unmeasured latent method factor test. A comparison between the standardized regression rates of the CFA model with and without the common latent factor (CLF) indicated that none of the regression weights were substantially affected by the CLF (the differences were all less than 0.1), indicating that common method bias did not affect the results.

To test the research hypotheses using SEM, we imputed data for the structural model and specified hypothesized paths between constructs based on the study model. This structural model had a chi-square value of 379.276 with 225 degrees of freedom, and a significant p-value of 0.00 . The model had a normed chi-square of 1.686, CFI of 0.964, RMSEA of 0.057, and SRMR of 0.043, all of which are within the range associated with a good fit (Hair et al., 2014). The validity of the structural model was assessed by comparing the fit indices of the structural model to that of the CFA model. The result demonstrated adequate validity, given that both fit indices were virtually the same, with no significant difference.

Table 1. Validity, reliability, and latent factor correlations

\begin{tabular}{ccccccccc}
\hline & CR & AVE & MSV & $\operatorname{MaxR}(\mathbf{H})$ & COG & CLB & BEH & EMO \\
\hline COG & 0.947 & 0.719 & 0.428 & 0.958 & $\mathbf{0 . 8 4 8}$ & & & \\
CLB & 0.887 & 0.530 & 0.399 & 0.892 & $0.631^{* * *}$ & $\mathbf{0 . 7 2 8}$ & & \\
BEH & 0.877 & 0.589 & 0.397 & 0.890 & $0.456^{* * *}$ & $0.403^{* * *}$ & $\mathbf{0 . 7 6 8}$ & \\
EMO & 0.980 & 0.925 & 0.428 & 0.983 & $0.654^{* * *}$ & $0.486^{* * *}$ & $0.630^{* * *}$ & $\mathbf{0 . 9 6 2}$ \\
\hline
\end{tabular}

Change Leadership Behaviors (CLB), Cognitive Appraisals (COG), Emotional Response (EMO), Behavioral Intentions (BEH), Composite Reliability (CR), Average Variance Extracted (AVE), Maximum shared variance $(\mathbf{M S V})$, Maximum reliability $(\operatorname{MaxR}(\mathbf{H}))$. ${ }^{* * *} \mathrm{p}<0.001$. Statistics in bold represent square root of respective AVEs 


\section{Results}

Hypotheses 1 was tested by examining the coefficients and p-values of each regression path between factors. Of the three hypothesized direct effects from change leadership to employee attitudinal reactions to change, only the path from change leadership behaviors to employee cognitive appraisal (H1a) was statistically significant at $\mathrm{p}<0.001$. The paths from change leadership to emotion response (H1b) and change leadership to intentions to support change (H1c), were not statistically significant. Table 2 gives a summary of direct effect results.

Table 2. Summary of hypothesized direct effects

\begin{tabular}{llccccc}
\hline No & Direct effects & Coefficients & S.E & CR & P & Conclusion \\
\hline H1a & Change leadership -->Cognitive appraisal & 0.632 & 0.128 & 8.614 & 0.001 & Supported \\
H1b & Change leadership --> Emotional response & 0.122 & 0.128 & 1.590 & 0.112 & Rejected \\
H1c & Change leadership --> Behavioral intentions & 0.127 & 0.069 & 1.735 & 0.083 & Rejected \\
\hline
\end{tabular}

Hypothesis 2 was tested using 'PROCESS' (5,000 bootstrap iterations). We tested for a sequential indirect relationship between change leadership and employee intentions to support the planned change. The results indicated that employee cognitive and emotional reactions to change serially mediated the relationship between change leadership and employee intentions to support planned change. This mediation test was statistically significant, evident in the fact that ' 0 ' falls outside the range between the lower limit confidence interval (0.137) and the upper limit of confidence interval (0.332). Table 3 shows a summary of the mediation results. A summary of the structural model results is presented in Figure 1.

\section{Table 3}

Summary of hypothesized mediation

Table 3. Summary of hypothesized mediation

\begin{tabular}{cccccc}
\hline No & Serial Mediation & Indirect effect & Upper limit & Lower limit & Conclusion \\
\hline H2 $\begin{array}{l}\text { Change leadership --> } \\
\text { Cognitive appraisal--> } \\
\text { Emotional response--> } \\
\text { Behavioral intentions }\end{array}$ & 0.228 & 0.332 & 0.137 & $\begin{array}{c}\text { Supported } \\
\text { (Serial mediation) }\end{array}$ \\
\hline
\end{tabular}




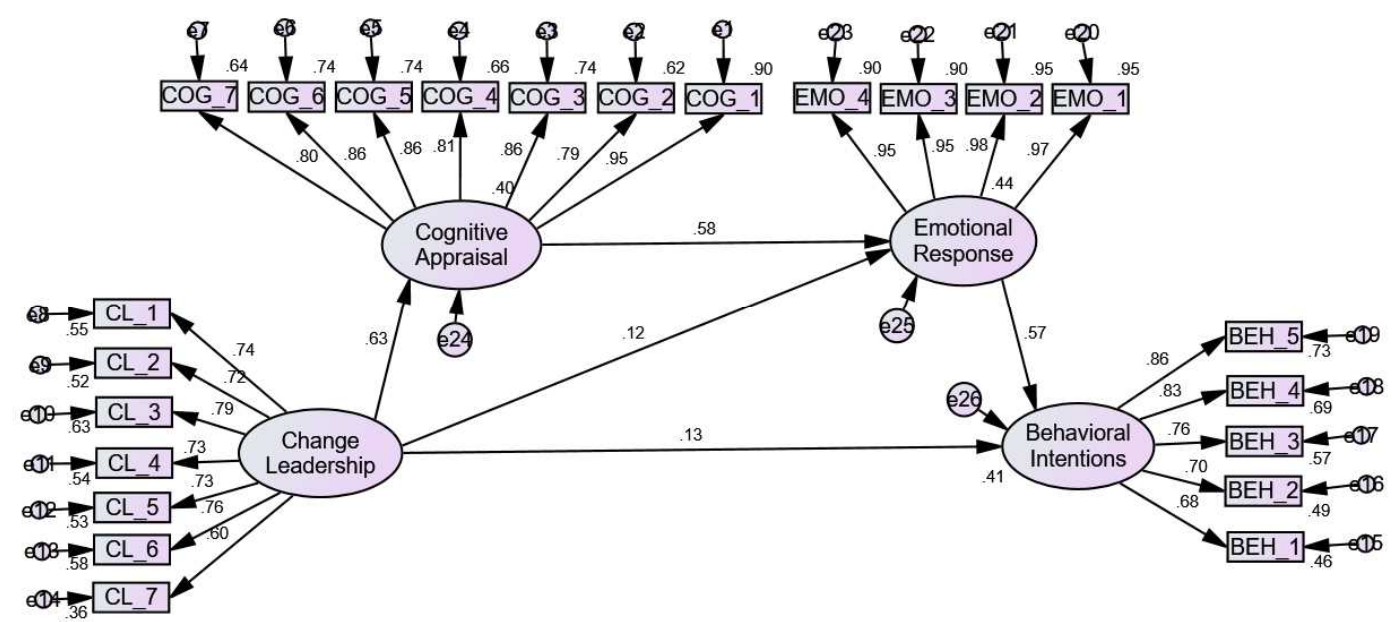

Figure 1. Structural Model Results (SEM)

\section{Discussion and Conclusion}

The general goal of this study was to examine the effect change leadership behaviors might have on employees' attitudinal reactions to change and to explain the overall process through which employee support for planned change is formed. In doing so, we applied change leadership measures (Herold et al., 2008) to predict employee attitudinal reactions to change (Piderit, 1999). We further extended the study by examining the relational ordering of employee attitudes towards change using a learning model of behavior change (Valente et al., 1998). This study yielded two essential findings.

First, the verification of hypothesis 1a shows that the primary target of change-related leadership behaviors during planned change events is to influence change participant's cognitions of the change at hand; it mainly affects employee reactions to change by emphasizing the value of change (Oreg and Berson, 2019). This finding is consistent with prior studies that found change leadership behaviors (change-selling behaviors) to be significantly related to affective commitment to change; a construct assessing employee mindsets towards a change event (Herold et al., 2008; Liu, 2010). The significant direct effect of change leadership on employee cognitive appraisal also underpins the claim that change recipients are guided by reason and will adopt a change if the change is logically justified to them (Szabla, 2007). Furthermore, it also concurs with prior studies that had shown that an individual's attitude towards an event is learned and cognitively driven and often results from the number of persuasive messages the individual is exposed to (Greenwald, 1968).

Contrary to expectations, the study could not verify Hypotheses $1 \mathrm{~b}$ and $1 \mathrm{c}$. We assume this is because change leadership is first and foremost, a persuasive and promotive process, through which change agents build the understanding of a change event. Change leadership behaviors are characterized as mostly enabling behaviors through which leaders provide a structure that guides 
followers' sensemaking of change (Higgs and Rowland, 2011). This could explain why change leadership directly influenced change participants' cognitions of change rather than their emotional or behavioral reactions. Although several qualitative research has argued that change leadership behaviors may affect follower's emotional response to change, very few empirical studies have tested such mechanisms. (Oreg and Berson, 2019). Also, studies show that change leadership requires both task and people-oriented behaviors (Battilana et al., 2010; Stouten et al., 2018). The change leadership behaviors explored in this study were somewhat task-oriented, in that the behaviors were mostly centered on the practical significance of the change. A significant amount of people-oriented behaviors such as, paying attention to subordinates' emotional needs, and encouraging subordinates to express a wider range of emotions (Huy, 2002), may be required to elicit favorable responses beyond cognition. This might explain why studies look to broader leadership conceptualizations (e.g., transformational leadership) or a combination of both (transformational and change leadership) to explain leadership effect on employee reactions to change. Given this understanding, we suppose that a more comprehensive sampling of change leadership behaviors may better reveal such relationships.

Second, this study showed that change leadership affects other dimensions of employee attitude towards change by influencing their cognitive appraisal of the change. By treating employee support for change as a multidimensional attitudinal construct, this study revealed how change leadership ultimately engenders employees' intention to support planned change. This 'intention' dimension of attitude is considered important because of its tendency to directly predict how people act or behave in response to change (Piderit, 2000). The results affirm that employees' cognitive appraisal and emotional response serially mediates the relationship between change leadership and employees' intentions to support planned change (H2). Change leadership helped shape employees' beliefs and understanding of the proposed change, which, in turn, influenced their emotional response towards the change, and employees' emotional response towards the change ultimately influenced their intentions to support or resist the change. These findings are consistent with other change literature, which suggests that change recipient's appraisal of change events is shaped by change contexts and processes and that such appraisals will exert influence on their affective and behavioral response to the change (Oreg et al., 2018).

\subsection{Research Implications}

This study is believed to have made several significant contributions to research. First, it has responded to Herold et al.'s (2008) call to examine the possible influence various types of leadership behaviors have on change participants' reactions to change. The effect of transformational leadership is well established in the leadership literature. However, research has paid only limited attention to change-related leadership contributions to reactions to change. Hence this study contributes to research by empirically validating the relevance of change leadership in influencing employee cognitive response to change. This also lends support to change leadership as proposed by research-oriented scholars (Herold et al., 2008) and the normative process models of change leadership as proposed by practice-oriented studies (Kotter, 2011). Furthermore, exploring employee support for change in the form of attitudinal dimensions allowed us to uncover the empirical link between change leadership and employee behavioral intentions to support 
change. Unearthing this relationship brings related researches a step closer to predicting overt employee behaviors towards change. Finally, the correlation between the three employee attitudinal reactions towards change suggests the possibility of bridging the silos that characterize the study of attitude-related issues in change. We show that a combination of isolated attitudinal concepts can, in research, prove a better way to study people's experiences of change.

Managerially, the findings of this research present relevant information that can help in the planning, implementation, and adoption of change. The study shows practitioners, managers, and change agents the salient role of employee attitudinal reactions (especially their cognitive appraisal of a proposed change) in building support for a planned change initiative. For a successful implementation of change, concerns of employees should be taken seriously since it is through their cooperation and actions that organizations can bring about the needed change. When reviewing and evaluating organizational efforts towards implementing a planned change, there is a tendency for managers to emphasize employee behaviors towards change instead of the conditions that drive such behaviors. This study shows change agents the need to focus on employee attitudinal reactions as precursors to such desired behavior towards change.

\subsection{Limitations and Recommendations}

This study has certain limitations under which the findings must be interpreted carefully. First of all, the study was conducted within a single organization (with multiple departments) and, as such, might raise concerns about the scalability and applicability of the results and findings. Specifically, we presume the susceptibility of our findings to cultural factors unique to the study sample. More multi-organizational studies would prove beneficial to this study.

Second, the study was cross-sectional, as it examined employee attitudinal reactions at a specific point in time within the change implementation process. Given that employee attitudes to change may evolve over time, paying attention to this evolution might yield insights about how to better manage change initiatives successfully. The study also could not investigate possible effects on overt behavioral reactions, given that it was carried out during the early stage of change implementation. Future studies may consider a longitudinal study design and investigate employee support for change at several stages in the change implementation continuum.

Finally, one could argue that the variable predicting employee support for change was not all-encompassing and that the observed hierarchy of effect over-simplifies the highly complex nature of employee attitude to change, given that attitude can be ordered in multiple ways (Valente et al., 1998). Future studies might consider including other leadership styles e.g., transformational leadership when investigating change leadership effect on employee attitudinal reactions to change, as such combinations may reveal a more holistic influence on employee attitudes towards change.

\section{References}

Armenakis, A. A., \& Bedeian, A.G. (1999). Organizational change: A review of theory and research in the 1990's. Journal of Management, 25(3), 293-315. https://doi.org/10.1177/014920639902500303 
Armenakis, A.A., Bernerth, J., Pitts, J., \& Walker, H. (2007). Organizational Change Recipients' Beliefs Scale. The Journal of Applied Behavioral Science, 43(4), 481-505. https://doi.org/10.1177/0021886307303654

Ashford, S. J. (1988). Individual strategies for coping with stress during organizational transitions. Journal of Applied Behavioral Science, 24(1), 19-36. https://doi.org/10.1177\%2F0021886388241005

Bailey, J., and Raelin, J. (2015). Organizations Don't Resist Change, People Do: Modeling Individual Reactions to Organizational Change through Loss and Terror Management. Organization Management Journal, 12(3), 125-138. https://doi.org/10.1080/15416518.2015.1039637

Bartunek, J. M., Rousseau, D. M., Rudolph, J. W., \& DePalma, J. A. (2006). On the receiving end: Sensemaking, emotion, and assessments of an organizational change initiated by others. Journal of Applied Behavioral Science, 42(2), 182-206. https://doi.org/10.1177/0021886305285455

Battilana, J., Gilmartin, M., Sengul, M., Pache, A., \& Alexander, J. (2010). Leadership competencies for implementing planned organizational change. The Leadership Quarterly, 21(3), 422-438. https://doi.org/10.1016/j.leaqua.2010.03.007

Beer, M., \& Nohria, N. (2000). Cracking the code of change, Harvard Business Review, 78(3), 133-141.

Burke, W.W. (2017), Organization Change: Theory and Practice, 5th ed., Sage Publications, Los Angeles.

Caldwell, S. D., Herold, D. M., \& Fedor, D. B. (2004). Towards an understanding of the relationships between organizational change, individual differences, and changes in person-environment fit: A cross-level study. Journal of Applied Psychology, 89(5), 868882. https://doi.org/10.1037/0021-9010.89.5.868

Choi, M. (2011). Employees' attitudes toward organizational change: A literature review. Human Resource Management, 50(4), 479-500. https://doi.org/10.1002/hrm.20434

Coyle-Shapiro, J. A. M. (1999). Employee participation and assessment of an organizational change intervention: A three-wave study of total quality management. Journal of Applied Behavioral Science, 35(4), 439-456. https://doi.org/10.1177\%2F0021886399354006

Dumas, C. and Beinecke, R.H. (2018), "Change leadership in the 21st century", Journal of Organizational Change Management, Vol. 31 No. 4, pp. 867-876. https://doi.org/10.1108/JOCM-02-2017-0042

Fishbein, M., \& Ajzen, I. (1975). Belief, attitude, intention, and behavior: an introduction to theory and research. Reading, MA: Addison-Wesley.

Greenwald, A. G. (1968). Cognitive learning, cognitive response to persuasion, and attitude change. In Greenwald, A. G., Brock, T. C., \& Ostrom T. M. (Eds.). Psychological Foundations of Attitudes. New York: Academic Press, 147-170.

Hair, J., Black, W., Babin, B., Anderson, R. (2014). Multivariate data analysis, 7th ed., Edinburgh Gate, Pearson Education Limited.

Herold, D. M. Fedor, D. B., Caldwell, S. D., \& Liu, Y. (2008). The effects of transformational leadership and change leadership on employee'se commitment to a change: A multi-Level study. Journal of Applied Psychology, 93(2), 346-357. https://doi.org/10.1037/0021$\underline{9010.93 .2 .346}$ 
Herscovitch, L., \& Meyer, J. P. (2002). Commitment to organizational change: Extension of a three-component model. Journal of Applied Psychology, 87(3), 474-487. https://doi.org/10.1037/0021-9010.87.3.474

Higgs, M., \& Rowland, D. (2005). All changes great and small: Exploring approaches to change and its leadership. Journal of Change Management, 5(2), 121-151. https://doi.org/10.1080/14697010500082902

Higgs, M., and Rowland, D. (2011). What does it take to implement change successfully? A study of the behaviors of successful change leaders, Journal of Applied Behavioral Science, Vol. 47 No. 3, pp. 309-335. https://doi.org/10.1177\%2F0021886311404556.

Hughes, M., and Ford, J. (2016). Change leadership: oxymoron and myths. Journal of Change Management, 16(1), 8-17. https://doi.org/10.1080/14697017.2016.1137425

Huy, Q. N. (2002). Emotional balancing of organizational continuity and radical change: The contribution of middle managers. Administrative Science Quarterly, 47(1), 31-69. https://doi.org/10.2307/3094890

Jones, R. A., Jimmieson, N. L., \& Griffiths, A. (2005). The impact of organizational culture and reshaping capabilities on change implementation success: The mediating role of readiness for change. Journal of Management Studies, 42(2), 361-386. https://doi.org/10.1111/j.1467-6486.2005.00500.x

Kiefer, T. (2005). Feeling bad: Antecedents and consequences of negative emotions in ongoing change. Journal of Organizational Behavior, 26(8), 875-897. https://doi.org/10.1002/job.339

Kotter, J. P. (1997). Leading change: A conversation with John P. Kotter. Strategy \& Leadership, 25(1), 18-23. https://doi.org/10.1108/eb054576

Kotter, J. P. (2011). "Change Management vs. Change Leadership - What's the Difference?" available at: https://www.forbes.com/sites/johnkotter/2011/07/12/change-managementvs-change-leadership-whats-the-difference/\#4e0bf95f4cc6

Liu, Y. (2010). When change leadership impacts commitment to change and when it doesn't: A multi-dimensional investigation. (Doctoral dissertation). Georgia Institute of Technology, USA. http://hdl.handle.net/1853/33856

Luo, W., Song, L.J., Gebert, D.R., Zhang, K. and Feng, Y. (2016), How does leader communication style promote employees' commitment at times of change? Journal of Organizational Change Management, Vol. 29 No. 2, pp. 242262. https://doi.org/10.1108/JOCM-11-2014-0204.

Norcross, J. C., Krebs, P. M., \& Prochaska, J. O. (2011). Stages of change. Journal of Clinical Psychology, 67(2), 143-154. https://doi.org/10.1002/jclp.20758

Oreg, S., Bartunek, J., Lee, G., \& Do, B. (2018). An affect-based model of recipient's responses to organizational change events. Academy of Management Review, 43(1), 65-86. https://doi.org/10.5465/amr.2014.0335

Oreg, S. and Berson, Y., (2019). Leaders' Impact on Organizational Change: Bridging Theoretical and Methodological Chasms. Academy of Management Annals, 13(1), pp.272307. https://doi/10.5465/annals.2016.0138 
Piderit, S. K. (1999). Navigating relationships with coworkers: Understanding employee's attitudes toward organizational change. Dissertation Abstracts International, 60(05), 1662. (UMI No. 9929921). In 'Szabla, D. (2007). A multidimensional view of resistance to organizational change: Exploring cognitive, emotional, and intentional responses to planned change across perceived change leadership strategies. Human Resource Development Quarterly, 18(4), 525-558. https://doi.org/10.1002/hrdq.1218

Piderit, S. K. (2000). Rethinking resistance and recognizing ambivalence: A multidimensional view of attitudes toward an organizational change. Academy of Management Review, 25(4), 783-794. https://doi.org/10.2307/259206

Podsakoff, P.M., MacKenzie, S.B., Lee, J.Y., and Podsakoff, N.P. (2003). Common method biases in behavioral research: a critical review of the literature and recommended remedies. Journal of Applied Psychology, 88(5), 879-903. https://doi.org/10.1037/0021$\underline{9010.88 .5 .879}$

Smollan, R. (2015). Causes of stress before, during and after organizational change: a qualitative study. Journal of Organizational Change Management, 28(2), 301-314. https://doi:10.1108/jocm-03-2014-0055

Stanley, D. J., Meyer, J. P., \& Topolnytsky, L. (2005). Employee cynicism and resistance to organizational change. Journal of Business and Psychology, 19(4), 429-459. https://doi.org/10.1007/s10869-005-4518-2

Stouten, J., Rousseau, D., \& De Cremer, D. (2018). Successful Organizational Change: Integrating the Management Practice and Scholarly Literatures. Academy Of Management Annals, 12(2), 752-788. https://doi:10.5465/annals.2016.0095

Szabla, D. (2007). A multidimensional view of resistance to organizational change: Exploring cognitive, emotional, and intentional responses to planned change across perceived change leadership strategies. Human Resource Development Quarterly, 18(4), 525-558. https://doi.org/10.1002/hrdq.1218

Valente, T., Paredes, P. \& Poppe, P. (1998). Matching the message to the process the relative ordering of knowledge, attitudes, and practices in behavior change research. Human Communication Research, 24(3), 366-385. https://doi.org/10.1111/j.14682958.1998.tb00421.x

Wanberg, C. R., and Banas, J. T. (2000). Predictors and outcomes of openness to changes in a reorganizing workplace. Journal of Applied Psychology, 85(1), 132-142. https://doi.org/10.1037/0021-9010.85.1.132

Weick, K., \& Quinn, R. (1999). Organizational change and development. Annual Review of Psychology, 50(1), 361-386. https://doi.org/10.1146/annurev.psych.50.1.361 